\title{
SOCIODRAMA ORGANIZACIONAL APLICADO PARA DESASTRES NATURAIS NO BRASIL
}

\author{
Harrysson Luiz da Silva ${ }^{1}$
}

Marcia Pereira Bernardes ${ }^{2}$

\section{INTRODUÇÃO}

No âmbito da administração pública brasileira, muito se tem avançado em controles e procedimentos. Entretanto, ainda persiste um modelo de estruturação de processos organizacionais, produtos, serviços, avaliação de objetivos, cumprimento de metas e responsabilidades, utilização de recursos físicos, humanos e financeiros, que impedem que se faça e se implante, qualquer tipo de gestão, que seja: a) eficaz na utilização dos recursos disponíveis; b) eficiente em termos do tempo utilizado; e, c) efetiva no que concerne às mudanças significativas de modo permanente. No âmbito da gestão de riscos e dos desastres naturais, tal constatação não é diferente se considerarmos o conjunto das instituições envolvidas nessas atividades.

Nessa perspectiva, as iniciativas nacionais e internacionais deflagradas para redução de riscos e desastres naturais que foram ratificadas pelo Brasil foram as seguintes: Estratégia Internacional de Redução de Riscos de Desastres Naturais (EIRD); a Política Nacional de Proteção e Defesa Civil (PNPDEC); o Protocolo de Hyogo 2015, e o Marco de Sendai pós 2015.

Nesse contexto há que se estabelecer a diferença entre "desastres naturais" e "desastres ambientais". Os desastres naturais, nosso foco de discussão, decorrem de fenômenos atmosféricos,

1 Professor Pós Doutor do Programa de Mestrado Profissional em Desastres Naturais do Departamento de Geociências da Universidade Federal de Santa Catarina. Realizando Curso de Especialização em Psicodrama pela Escola Locus. E-mail: harrysson@uol. com.br

2 Doutoranda em Psicologia no Departamento de Psicologia da Universidade Federal de Santa Catarina em Saúde do Trabalhador em Situação de Desastres Naturais. Professora e Diretora da Escola Locus de Psicodrama. Psicodramatista Didata Supervisora pela FEBRAP. E-mail: marcia@locuspsicodrama.com.br 
tectônicos, etc. Já os desastres ambientais, em sua grande maioria, são decorrentes da inexistência de sistema de gestão ambiental, de controle e monitoramento de indicadores, mesmo em situações de eventos extremos, promovendo a descontinuidade das atividades dos diferentes públicos-alvo, dentre eles, as empresas e seus negócios, como o que aconteceu no município de Mariana, no Estado de Minas Gerais, através da Empresa SAMARCO.

Em contrapartida, o documento denominado "Diagnóstico e Análise das Necessidades de Formação em Gestão de Riscos e de Desastres" da Secretaria de Defesa Civil - SEDEC, do Ministério da Integração Nacional, e do Programa das Nações Unidas para o Desenvolvimento - PNUD apontou inúmeras não conformidades, relativas aos processos de institucionalização da Proteção e Defesa Civil no Brasil, em relação às declarações, marcos, estratégias e políticas em processo de implantação, conforme descrito anteriormente.

Da mesma forma, conforme a referida PNPDEC, existem objetivos comuns que deverão ser seguidos pelas diferentes instâncias de gestão de riscos e de desastres naturais, quais sejam: União, Estados e Municípios. No âmbito das competências comuns (administrativas) e concorrentes (legislativas), as referidas instâncias de gestão têm competências específicas, que por si só, são geradoras de conflitos não só institucionais, internamente, mas também interinstitucionais diversos.

Antes de tudo, porém, é preciso caracterizar que as próprias instâncias, que operam a gestão de riscos e dos desastres naturais no Brasil, se reconheçam internamente num primeiro momento, para que a PNPDEC seja efetiva enquanto política pública num segundo momento, a partir do seu reconhecimento mútuo até o encontro.

A "mobilização para ação", por sua vez, se constituiu numa das variáveis descritas nas declarações, marcos, estratégias e políticas, e, que deverá ser objeto de intervenção para promover os processos de gestão e de defesa civil no Brasil.

O caráter teórico dos processos de formação em gestão de riscos e desastres ambientais, realizados no Brasil até o presente momento, foi também uma das principais características que impediram os agentes públicos, de se tornarem capazes do desenvol- 
vimento de ações orientadas para situações de desastres naturais, conforme relatório SEDEC/PNUD (2014).

Mesmo considerando o diagnóstico da necessidade de formação já realizado, ainda assim, não se tem um diagnóstico organizacional de forma detalhada e fundamentada, das instituições envolvidas em gestão de riscos e de desastres naturais, bem como, uma metodologia que mobilize os agentes públicos e comunidades, para ações de desastres naturais, diante das demandas e necessidades levantadas pelo documento da SEDEC/PNUD (2014).

Há que se estabelecer o "encontro"3" entre as instituições que operam a gestão de riscos e de desastres naturais, não só através de suas demandas, como também através da verificação do acolhimento dessas demandas regionais, a partir dos diferentes estágios de desenvolvimento da matriz de identidade das suas referidas instituições.

As demandas de formação em gestão de riscos e de desastres naturais, bem como a necessidade de realização do diagnóstico organizacional através de métodos e técnicas sociodramáticas, deverão ser utilizadas para que se possa propor num segundo momento, um conjunto de diretrizes para cada uma das 7 (sete) não conformidades encontradas no documento produzido pelo SEDEC/PNUD (2014).

Da mesma forma, o diagnóstico organizacional irá dimensionar em que medida, as instituições que promovem a gestão dos riscos e dos desastres ambientais no Brasil estão preparadas e/ou organizadas para atenderem/internalizarem as necessidades de formação levantadas pelo Relatório do SEDEC/PNUD (2014).

Assim, não adianta somente criar políticas públicas. É preciso criar as condições institucionais para que elas possam ser operacionalizadas em toda a sua extensão. Se isso não ocorre com efetividade com as políticas setoriais, mais difícil será com as politicas públicas integradas, como é o caso da Política Nacional de Proteção e Defesa Civil. Para tanto, se coloca a seguinte hipótese de investigação: as demandas de necessidades de formação em gestão de riscos

3 Conforme FONSECA FILHO (1980), o "encontro" seria a última das 10 (dez) etapas do desenvolvimento da matriz de identidade, no caso em discussão, do reconhecimento das instituições envolvidas na gestão de riscos e de desastres naturais, num processo de gestão total da inversão de suas competências comuns e concorrentes. 
de desastres naturais no Brasil só acontecerão de modo eficaz, eficiente e efetivo, se a partir de um diagnóstico organizacional se encontrar os "gaps", que tornarão possível se estabelecer uma relação entre o nível de organização da estrutura das respectivas instituições e suas respectivas demandas de processos de formação, mobilizando os agentes públicos para a ação em caso de desastres naturais.

Através do diagnóstico organizacional, será possível identificar os níveis de integração necessários para que as políticas públicas e as respectivas instituições envolvidas promovam programas de formação intersetorial de gestão de riscos e de desastres ambientais, o que ainda não ocorre no Brasil.

Se as instituições ainda apresentam diferentes "níveis de desenvolvimento de sua matriz de identidade institucional" ${ }^{4}$, não poderão, em curto prazo, possibilitar que demandas de determinados níveis de formação e de reconhecimento de outras instituições sejam exequíveis, já que a "mobilização para a ação" decorrentes desses processos de formação é resultante de todos os recursos dessa estrutura que sequer está organizada, e que ainda não se reconhece internamente como tal, nessa atividade.

Urge avançar nessa perspectiva ${ }^{5}$, já que existe demanda qualificada para essa atividade, não só visando a institucionalização das declarações, marcos, estratégias e políticas, mas também a mobilização para ação das comunidades e dos agentes públicos.

Por sua vez, o fortalecimento da cultura organizacional de gestão de riscos e de desastres naturais, pelas instituições envolvidas nessa atividade, bem como, da percepção de riscos e de desastres das populações objeto das ações dessas instituições, ainda estão em fase embrionária, precisando de uma ação mobilizadora para situações em eventos extremos.

Diante dessa sociodinâmica, e com base no diagnóstico do SEDEC/PNUD (2014), levantou-se "aqui e agora" o seguinte problema de investigação: a aplicação do sociodrama organizacional

4 A matriz de identidade institucional é aquela que integra as diferentes etapas de institucionalização da PNPDEC.

5 Para avançar nessa perspectiva, no ano de 2014, a partir de iniciativas do Ministério da Integração Nacional, foram criados cursos de Mestrado Profissional em Desastres Naturais no Brasil, sendo um deles na Universidade Federal de Santa Catarina - UFSC. A criação desses cursos tem por objetivos, a formação de quadros técnicos orientados para gestão de riscos e de desastres naturais, nas diferentes escalas de gestão dos desastres naturais (municipal estadual e federal). 
como método de ação, tornaria possivel através de suas técnicas, um diagnóstico organizacional, no âmbito das instituições de todas as unidades da federação envolvidas na gestão de riscos e de desastres naturais, em suas diferentes escalas de atuação (federal, estadual e municipal), tornando possível a institucionalização da Política Nacional de Proteção e Defesa Civil no Brasil e a mobilização dos agentes públicos para ações integradas num contexto de desastres naturais?

A mobilização para ação, por ser um dos princípios fundantes da socionomia, que dará base para intervenção através do sociodrama, se constituiu na fundamentação e metodologia de intervenção selecionada pelos autores, por ser a mais adequada, para responder tanto o contexto já levantado, quanto a hipótese de investigação e o problema de pesquisa descrito.

Para fins de efetivação de um processo de gestão da PNPDEC, utilizar-se-á a "teoria do desenvolvimento da matriz de identidade ${ }^{6 \text { " }}$ aplicada para fins institucionais, como recurso para desenvolvimento de um sistema de gestão da PNPDEC, desde a sua fase inicial, demarcada pelo diagnóstico organizacional a partir do sociodrama, e de técnicas que serão utilizadas para proposição de diretrizes ${ }^{7}$.

Para responder esse problema de investigação, organizou-se a estrutura desse artigo na seguinte estrutura: a) na primeira parte serão discutidas as premissas da Política Nacional de Proteção e Defesa Civil, e os resultados da avaliação pelo PNUD das ações de proteção e defesa civil no Brasil, bem como, as responsabilidades da União, Estados e municípios na gestão de riscos e de desastres naturais; b) na segunda parte será caracterizada a fundamentação teórica que norteará a discussão dos desastres naturais no âmbito organizacional; e, c) na terceira parte serão analisadas, na perspectiva do sociodrama organizacional, as não conformidades já levantadas pelo SEDEC/PNUD (2014), e, as diretrizes de plane-

6 A teoria do desenvolvimento da matriz de identidade é parte da socionomia e que é utilizada para identificar estágios de desenvolvimento de grupos, instituições e indivíduos, tendo como objetivo, através da investigação sociométrica, encontrar os recursos de intervenção sociátrica que possibilitarão o "encontro" das diferentes instituições em suas diferentes escalas espaciais de atribuições, responsabilidades e competências.

7 DATNER, Yvette. Jogos para educação empresarial: jogos, jogos dramáticos, role playing e jogos de empresa. São Paulo. Agora, 2006, 142 p. 
jamento que serão propostas para as instituições envolvidas na proteção e defesa civil da gestão de riscos e de desastres naturais no Brasil, a partir da integração dos seus 16 (dezesseis) objetivos, com os 7 (sete) resultados das sondagens realizadas pelo SEDEC/ PNUD (2014).

Convém ressaltar que, nesse artigo, não será discutido extensivamente a Teoria da Matriz de Identidade aplicada para instituições relacionadas à gestão de riscos e de desastres naturais. Da mesma forma, nesse artigo não será esgotado essa temática tão complexa e extensa, que certamente suscitará novos desdobramentos a partir da proposição das diretrizes.

Espera-se que todas as considerações descritas anteriormente despertem a emergência do fortalecimento da cultura organizacional para gestão de riscos e de desastres naturais, e, que o sociodrama organizacional, através das técnicas psicodramáticas utilizadas para diagnóstico organizacional, seja considerado um recurso para levantamento das demandas e necessidades tanto das instituições, bem como, dos agentes públicos envolvidos na gestão de riscos e de desastres ambientais das mais variadas áreas do conhecimento.

\section{A POLÍTICA NACIONAL DE PROTEÇÃO E DEFESA CIVIL E A AVALIAÇÃO DO PROGRAMA DAS NAÇÕES UNIDAS PARA O DESENVOLVIMENTO - PNUD}

\section{A Política Nacional de Proteção e Defesa Civil}

A Política Nacional de Proteção e Defesa Civil no Brasil foi aprovada no ano de 2012. Considerando a complexidade da estrutura das competências comuns (administrativas) e concorrentes (legislativas) que interseccionam a União, Estados e municípios, já de início a referida Lei estabelece o ciclo PDCA (planejar, decidir, corrigir e agir) como instrumento para gestão, que se traduzem nas etapas da proteção e defesa civil no Brasil: prevenção, mitigação, preparação, resposta e recuperação. Assim será necessário planejar, decidir, corrigir e agir em cada uma das etapas do ciclo da proteção e da defesa civil descrita acima. 
Convêm ressaltar, que para cada uma das etapas do ciclo PDCA da proteção e defesa civil, estão atreladas diferentes instituições, do governo federal, estadual e municipal, com diferentes níveis de atribuições e competências comuns e concorrentes. Esse contexto por sí só, já é um complicador para um processo de gestão integrada.

Inicialmente já se verifica que é preciso considerar dois contextos de ocorrência de cada etapa da proteção e da defesa civil no âmbito do ciclo PDCA, conforme será descrito a seguir: a) o referido ciclo deverá estar integrado como estrutura de cada uma das etapas; e, b) o ciclo deverá estar integrado no conjunto das ações relativas à proteção e defesa civil. Qual a diferença em termos de gestão para uma política de proteção e defesa civil, entre "a" e "b"?

Quando se utiliza o "ciclo pdca" no caso "a", se tem uma compreensão mais precisa de cada etapa da proteção e da defesa civil, bem como, da identificação dos gaps em cada etapa, de cada instituição a partir de suas respectivas atribuições e competências.

Quando se utiliza o ciclo "pdca" no caso "b" tem-se a compreensão do resultado final, sem o reconhecimento se houve algum tipo de problema em algum momento que possa comprometer o resultado final. Da mesma forma, se o resultado final for comprometido, nunca se saberá em que etapa o problema ocorreu, a não ser que se faça nova investigação.

No âmbito das discussões relacionadas à gestão das etapas da proteção e defesa civil, recomenda-se que os diagnósticos organizacionais sociodramáticos estejam prioritariamente envolvidos, com o caso tipo 'a".

A seleção do caso tipo "a' é o mais recomendado nesse contexto, considerando, que em cada instituição, existe uma cultura organizacional diferenciada, que por não ser compreendida, promove a desmobilização dos agentes públicos para ação, impedindo-se uma intervenção sociométrica/sociátrica com controle de resultados e monitoramento, junto aos seus diferentes interlocutores, dentre os quais, outras instituições.

Em linhas gerais, a Política Nacional de Proteção e Defesa Civil precisará integrar todas as instituições nas diferentes escalas de gestão federais, estaduais e municipais, que tenham relação direta com as seguintes políticas públicas, tendo em vista, o desenvolvimento sustentável: ordenamento territorial, desenvolvimento urbano, 
saúde, meio ambiente, mudanças climáticas, gestão de recursos hídricos, geologia, infraestrutura, educação, ciência e tecnologia e às demais políticas setoriais.

Concomitantemente, se a PNPDEC prevê a integração, essa ocorrência deverá ser considerada quando da convocação dos agentes públicos para desenvolvimento de ações concretas, relativas ao sociodrama organizacional, e seu grau de participação numa etapa de proteção e de defesa civil, orientando a "mobilização para ação" em situações de desastres naturais.

Assim, o diagnóstico organizacional sociodramático não deverá deixar de considerar, não só a capacidade de integração, como também as ações integradas das instituições envolvidas na proteção e defesa civil e de seus diferentes públicos-alvo.

Por sua vez, cada etapa da politica de proteção e de defesa civil, deverá se internalizar promovendo ações que estejam voltadas para atingir os seguintes objetivos ${ }^{8}$ :

a) reduzir os riscos de desastres; b) prestar socorro e assistência às populações atingidas nos desastres; $c$ ) recuperar as áreas afetadas por desastres; d) incorporar a redução do risco de desastre e as ações de proteção e defesa civil entre os elementos da gestão territorial e do planejamento das políticas setoriais; e) promover a continuidade das ações de proteção e defesa civil; f) estimular o desenvolvimento de cidades resilientes e os processos sustentáveis de urbanização; g) promover a identificação e avaliação das ameaças, suscetibilidades e vulnerabilidades a desastres, de modo a evitar ou reduzir sua ocorrência; h) monitorar os eventos meteorológicos, hidrológicos, geológicos, biológicos, nucleares, químicos e outros potencialmente causadores de desastres; i) produzir alertas antecipados sobre a possibilidade de ocorrência de desastres naturais; j) estimular o ordenamento da ocupação do solo urbano e rural, tendo em vista sua conservação e a proteção da vegetação nativa, dos recursos hídricos e da vida humana; k) combater a ocupação de áreas ambientalmente

8 BRASIL. Lei n. 12.608, de 10 de Abril de 2012. Institui a Política Nacional de Proteção e Defesa Civil - PNPDEC; dispõe sobre o Sistema Nacional de Proteção e Defesa Civil - SINPDEC e o Conselho Nacional de Proteção e Defesa Civil - CONPDEC; autoriza a criação de sistema de informações e monitoramento de desastres. Disponível em: http://www.planalto.gov.br/ccivil 03/ ato2011-2014/2012/lei/l12608.htm, acesso em 16/04/2017. 
vulneráveis e de risco e promover a realocação da população residente nessas áreas; I) estimular iniciativas que resultem na destinação de moradia em local seguro; $k$ ) desenvolver consciência nacional acerca dos riscos de desastres; $m$ ) orientar as comunidades a adotarem comportamentos adequados de prevenção e de resposta em situação de desastre e promover a autoproteção; e, n) integrar informações em sistema capaz de subsidiar os órgãos do SINPDEC na previsão e no controle dos efeitos negativos de eventos adversos sobre a população, os bens e serviços e o meio ambiente.

No âmbito da gestão das competências, conforme a PNPDEC ${ }^{9}$ para que a mobilização das ações se dê de forma coordenada é preciso que a União, o Estado e os municípios estejam em plena atividade, para isso é necessário que:

- União: a) expeça normas para implantação e execução da PNPDEC; b) coordene o SINPDEC, em articulação com os Estados, o Distrito Federal e os Municípios; c) promova estudos referentes às causas e possibilidades de ocorrência de desastres de qualquer origem, sua incidência, extensão e consequência; d) apoie os Estados, o Distrito Federal e os Municípios no mapeamento das áreas de risco, nos estudos de identificação de ameaças, suscetibilidades, vulnerabilidades e risco de desastre e nas demais ações de prevenção, mitigação, preparação, resposta e recuperação; e) institua e mantenha sistema de informações e monitoramento de desastres; institua e mantenha cadastro nacional de municípios com áreas suscetíveis à ocorrência de deslizamentos de grande impacto, inundações bruscas ou processos geológicos ou hidrológicos correlatos; f) institua e mantenha sistema para declaração e reconhecimento de situação de emergência ou de estado de calamidade pública; $g$ ) instituir o Plano Nacional de Proteção e Defesa Civil; h) realize o monitoramento meteorológico, hidrológico e geológico das áreas de

9 BRASIL. Lei n. 12.608, de 10 de Abril de 2012. Institui a Política Nacional de Proteção e Defesa Civil - PNPDEC; dispõe sobre o Sistema Nacional de Proteção e Defesa Civil - SINPDEC e o Conselho Nacional de Proteção e Defesa Civil - CONPDEC; autoriza a criação de sistema de informações e monitoramento de desastres. Disponível em: http://www.planalto.gov.br/ccivil 03/ ato2011-2014/2012/lei/l12608.htm, acesso em 16/04/2017. 
risco, bem como, dos riscos biológicos, nucleares e químicos, e produzir alertas sobre a possibilidade de ocorrência de desastres, em articulação com os Estados, o Distrito Federal e os Municípios; i) estabeleça critérios e condições para a declaração e o reconhecimento de situações de emergência e estado de calamidade pública; j) incentive a instalação de centros universitários de ensino e pesquisa sobre desastres e de núcleos multidisciplinares de ensino permanente e a distância, destinados à pesquisa, extensão e capacitação de recursos humanos, com vistas no gerenciamento e na execução de atividades de proteção e defesa civil; k) fomente a pesquisa sobre os eventos deflagradores de desastres; e, I) apoie a comunidade docente no desenvolvimento de material didático-pedagógico relacionado ao desenvolvimento da cultura de prevenção de desastres;

- $\quad$ Estados: a) execute a PNPDEC em seu âmbito territorial; b) coordene as ações do SINPDEC em articulação com a União e os Municípios; c) instituir o Plano Estadual de Proteção e Defesa Civil; d) identifique e mapeie as áreas de risco e realizar estudos de identificação de ameaças, suscetibilidades e vulnerabilidades, em articulação com a União e os Municípios; f) realize o monitoramento meteorológico, hidrológico e geológico das áreas de risco, em articulação com a União e os Municípios; j) apoie a União, no reconhecimento de situação de emergência e estado de calamidade pública quando solicitado; k) declare, quando for o caso, estado de calamidade pública ou situação de emergência; e, L) apoie, sempre que necessário, os Municípios no levantamento das áreas de risco, na elaboração dos Planos de Contingência de Proteção e Defesa Civil e na divulgação de protocolos de prevenção e alerta e de ações emergenciais.

- Municípios: a) executem a PNPDEC em âmbito local; b) coordenem as ações do SINPDEC no âmbito local, em articulação com a União e os Estados; c) incorporem ações de proteção e defesa civil no planejamento municipal; d) identificar e mapear as áreas de risco de desastres; e) promover a fiscalização das áreas de risco de desastre e vedar novas ocupações nessas áreas; f) declarar situação de emergência e estado de calamidade pública; g) vistoriar edificações e áreas de risco e promover, quando for o caso, a intervenção preventiva 
e a evacuação da população das áreas de alto risco ou das edificações vulneráveis; $h$ ) organizar e administrar abrigos provisórios para assistência à população em situação de desastre, em condições adequadas de higiene e segurança; i) manter a população informada sobre áreas de risco e ocorrência de eventos extremos, bem com, sobre protocolos de prevenção e alerta e sobre as ações emergenciais em circunstâncias de desastres; j) mobilizar e capacitar os radioamadores para atuação na ocorrência de desastre; $k$ ) realizar regularmente exercícios simulados, conforme Plano de Contingência de Proteção e Defesa Civil; I) promover a coleta, a distribuição e o controle de suprimentos em situações de desastre; $m$ ) proceder à avaliação de danos e prejuízos das áreas atingidas por desastres; n) manter a União e o Estado informados sobre a ocorrência de desastres e as atividades de proteção civil no Município; o) estimular a participação de entidades privadas, associações de voluntários, clubes de serviços, organizações não governamentais e associações de classe e comunitárias nas ações do SINPDEC e promover o treinamento de associações de voluntários para atuação conjunta com as comunidades apoiadas; e, p) prover solução de moradia temporária às famílias atingidas por desastres;

- Por sua vez, compete reflexivamente à União, aos Estados e aos Municípios: a) desenvolver cultura nacional de prevenção de desastres, destinada ao desenvolvimento da consciência nacional acerca dos riscos de desastre no País; $b$ ) estimular comportamentos de prevenção capazes de evitar ou minimizar a ocorrência de desastres; c) estimular a reorganização do setor produtivo e a reestruturação econômica das áreas atingidas por desastres; d) estabelecer medidas preventivas de segurança contra desastres em escolas e hospitais situados em áreas de risco; f) oferecer capacitação de recursos humanos para as ações de proteção e defesa civil; e, g) fornecer dados e informações para o sistema nacional de informações e monitoramento de desastres.

Assim, a compreensão socionômica dos desastres naturais deverá tomar a sociodinâmica já discutida anteriormente, e através do diagnóstico organizacional utilizando o sociodrama como método, os jogos dramáticos e as técnicas como meio de discutir na segunda parte, quais deverão ser as medidas a serem tomadas 
nos diferentes estágios da matriz de identidade das diferentes instituições com fins sociátricos, visando: redução de conflitos de competência comum e concorrente; controle de resultados e de monitoramento; redução do Estresse e do "Transtorno de Estresse Pós Traumático - TEPT" decorrentes de ações em eventos extremos; objetivos a serem atingidos; construção de sociedades e instituições mais resilientes.

Os diagnósticos organizacionais sociodramáticos deverão trazer avaliações que deverão ser operacionalizadas para redução de riscos e de desastres naturais, ameaças e vulnerabilidades, compondo um conjunto de diretrizes, que deverão ter não somente caráter de intervenção, a partir de avaliação sociométrica, quanto também resultados sociátricos, nas instituições envolvidas em sua relação interna com os diferentes públicos-alvo.

A partir da figura 1 pode-se concretizar o conjunto das varáveis que estruturam o fenômeno em discussão, bem como, o que deverá envolver o diagnóstico organizacional sociodramático decorrente da PNPDEC, e as variáveis que deverão ser observadas para identificação de respostas novas, para a situação colocada pelas novas exigências, com vistas a atender o cumprimento das competências de cada esfera de poder, dos objetivos e dos resultados esperados.

Até o presente momento todas as variáveis da Figura 1 estão isoladas em termos de uma Política Integrada de Proteção e Defesa Civil, que se reflete, na legislação das competências comuns e concorrentes, nos organogramas funcionais das diferentes instituições, nos modelos de gestão dos agentes públicos e na conservação cultural de adoção de procedimentos operacionais empíricos sem fundamentação, controle e monitoramento de resultados.

Pode-se constatar a quantidade de objetivos, atividades de gestão, natureza e estrutura dos marcos regulatórios, etapas da proteção e da defesa civil, níveis de gestão, escalas espaciais de intervenção, que exigirão não só uma logística (deslocamento espacial) quanto uma tempística (administração do tempo de mudança) para orientar tomadas de decisão em situação de desastres naturais, a partir do atendimento ás políticas públicas considerando os setores envolvidos. 


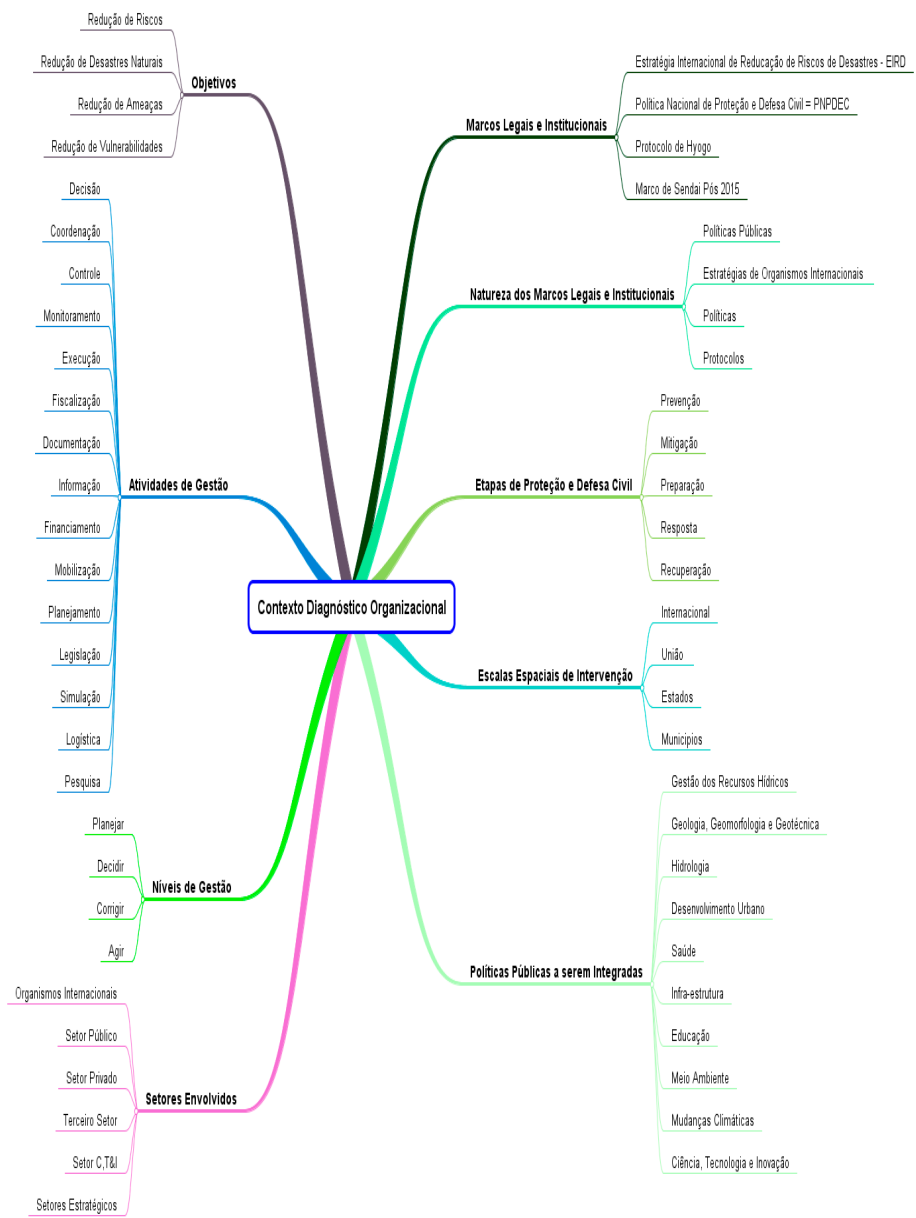

Figura 1 - Contexto para Diagnóstico Organizacional Sociodramático.

Fonte: Organizado pelos autores, a partir de revisão bibliográfica, dos marcos legais e institucionais, 2017.

Para que a PNPDEC seja executada em sua plenitude as instituições envolvidas na proteção e na defesa civil no âmbito organizacional deverão se reconhecer enquanto estrutura operacional, bem como, de suas atribuições e responsabilidades relativas à gestão de riscos e de desastres naturais.

Se as instituições ainda não se reconhecem em termos de sua estrutura organizacional, nem internamente, nem externamente, 
numa ação integrada em termos de controle de resultados, como garantir processos de formação de pessoal em gestão de riscos e de desastres naturais, isolados do ambiente, onde operacionalmente essas atividades serão desenvolvidas.

Dessa forma, se reforça a necessidade de diagnóstico organizacional intersetorial, a partir do sociodrama, trazendo contribuições efetivas para que não só a estrutura organizacional das referidas instituições sejam reconhecidas entre si num primeiro momento, e constatem diferentes níveis de complementariedade que poderão ser desenvolvidos, sem a necessidade de ampliação de papéis funcionais dos diferentes agentes públicos e duplicação de estruturas organizacionais.

Portanto, será nessa perspectiva que atribuições, responsabilidades, papéis funcionais e profissionais deverão ser integrados, visando atingir os objetivos da PNPDEC.

A compreensão dos desastres naturais numa perspectiva socionômica, ou seja, das relações humanas sobre o espaço geográfico, bem como, as relações assimétricas analisadas pela sociometria, e o reconhecimento de problemas que deverão ser resolvidos no âmbito sociátrico, certificam o sociodrama e seu respectivo modelo de diagnóstico organizacional, como recurso para compreensão e integração das políticas públicas de desastres naturais.

A seguir serão apresentados os resultados da avaliação da SEDEC/PNUD (2014) realizado em 10 (dez) Estados brasileiros, relativo à formação em gestão de riscos e de desastres naturais.

\section{A Avaliação do PNUD das Ações de Proteção e Defesa Civil no Brasil}

No ano de 2014 a Secretaria Nacional de Proteção e defesa Civil do Ministério da Integração, juntamente com o Programa das Nações Unidas para o Desenvolvimento, lançaram o documento intitulado "Diagnóstico e Análise das Necessidades de Formação em Gestão de Riscos e de Desastres". Esse diagnóstico foi realizado em 10 (dez) Estados da federação, com o objetivo de avaliar o status atual da formação em gestão de riscos e de desastres no país, mais precisamente: Rio Grande do Sul, Santa Catarina, Paraná, São Paulo, Rio de Janeiro, Espírito Santo, Minas Gerais, Bahia, Alagoas 
e Pernambuco. A metodologia utilizada pautou-se em sondagens como linha de base, entrevistas e oficinas para fins de avaliação.

$\mathrm{Na}$ sondagem inicial, enquanto primeira etapa do projeto foram identificados 7 (sete) níveis de avaliação, que serão descritos a seguir: a) familiaridade com a Lei $12.608 / 2012$, que se refere sobre a Política Nacional de Proteção e Defesa Civil, bem como, com o Sistema Nacional de Proteção e Defesa Civil - SINPDEC; b) conhecimento e capacidade para a articulação interinstitucional (vertical e horizontal); c) determinação de riscos e formulação de medidas para redução de riscos no seu município e Estado; d) capacidades técnicas nas etapas da proteção e defesa civil, quais sejam: prevenção, preparação, resposta e recuperação. Não foi avaliada a capacidade para mitigação, já que está é uma discussão ainda não consensual, entre agentes públicos, sobre os níveis de sua "obrigação de fazer"; e) nível de cobertura temática do processo de formação por Estado; f) níveis de acesso às informações sobre proteção e defesa civil; e, g) necessidade de formação em proteção e defesa civil.

Com relação ao item "a" descrito acima, o resultado da sondagem inicial foi o seguinte: a) do público alvo pesquisado $69,2 \%$ afirmaram ter familiaridade com a Lei 12.608/2012. No que se refere á Política Nacional de Proteção e Defesa Civil, 47,8\% declararam ter algum conhecimento, o que não ocorre com $26,4 \%$ dos entrevistados que desconhecem o Plano Nacional de gestão de Riscos e de Desastres.

Convém ressaltar que ter conhecimento da PNPDEC não significa que a implantação seja correspondente. Nessa mesma perspectiva, $87 \%$ declararam ter um conhecimento de muito baixo a médio respectivamente: sobre o mandato, a composição, as funções do SINDPEC relativos à redução de riscos. Somente $13 \%$ dos entrevistados no conjunto dos 10 (dez) Estados pesquisados tinham um conhecimento alto sobre a legislação e o SINDPEC.

Com relação ao item "b" descrito acima, o resultado da sondagem inicial foi o seguinte: a) acima de $70 \%$ dos entrevistados para o conjunto dos Estados pesquisados não tem conhecimento, nem capacidade suficiente para iniciar a participação, e a articulação interinstitucional tanto aos níveis das esferas de governo, quanto ao nível comunitário. 
Esse resultado demonstra a necessidade de atividades orientadas, para "mobilizar agentes públicos para à ação", em situação de gestão de riscos e desastres naturais; b) mais de $60 \%$ dos agentes públicos não tem conhecimento técnico para realização de diagnósticos e análises que exijam expertise dirigida e passível de supervisão; c) com relação à formulação de planejamento de políticas, planos, programas e projetos, mais de $70 \%$ não tem conhecimento e capacidade para realização de tais processos operacionais; d) no que concerne a coordenações de ações, mais de $70 \%$ dos entrevistados demarcaram que não estão habilitados para tal atividade. Esse resultado reforça a falta de preparação para a ação no caso de um desastre natural; e), âmbito da gestão, orçamento, desenvolvimento, implantação de intervenções, bem como, na provisão de serviços, os agentes públicos se colocaram num patamar entre 60 a $81 \%$ de falta de condições, conhecimentos para o desenvolvimento dessas atividades.

Com relação ao item "c" descrito acima, o resultado da sondagem inicial foi o seguinte: a) na parte relativa à gestão de riscos, $77 \%$ dos entrevistados consideram-se aptos para tal atividade, embora 23\% afirmaram não ter capacidade para gestão.

Essa avaliação reforça o desconhecimento tanto interno, quanto externo dos agentes públicos das competências comuns e concorrentes das instituições envolvidas na gestão de riscos e de desastres naturais.

Com relação ao item "d" descrito acima, o resultado da sondagem inicial foi o seguinte: a) a capacidade técnica está ausente em $70 \%$ dos entrevistados, o que compromete todo o ciclo de proteção e defesa civil, e concomitantemente a mobilização para a ação.

Essa avaliação deixa mais do evidente, a falta de preparação para ação dos agentes públicos, quando em situação de eventos extremos, a sua ação não se torna operacional.

Com relação ao item "e" descrito acima, o resultado da sondagem inicial foi o seguinte: a) $50 \%$ dos pesquisados afirmou ter recebido formação no tema sobre a etapa de recuperação, e 85\% em prevenção, faltando respectivamente, em ambos os casos, o conjunto das 4 (quatro etapas da proteção e defesa civil: prevenção, preparação, resposta e recuperação). Segundo informações do Diagnóstico a rotatividade na área de proteção e defesa civil 
é um óbice para a criação de cultura de riscos e desastres nessas instituições.

A falta de etapas de formação do ciclo da proteção e da defesa civil impede que os agentes públicos, tenham uma compreensão completa de todo o processo, não só organizacionalmente, como também operacionalmente, trazendo para os mesmos impedimentos relativos ao desenvolvimento de suas atividades operacionais em situação de eventos extremos.

Com relação ao item " $f$ " descrito acima, o resultado da sondagem inicial foi o seguinte: a) com relação à possibilidade de acesso aos cursos de formação em gestão de riscos e de desastres, de $60 \%$ a $75 \%$ dos entrevistados afirmam ter dificuldades aos cursos existentes. A localização dos cursos e a distância de suas unidades administrativas impedem os mesmos de participarem, bem como, das dificuldades interpostas pelas instituições com poucos quadros técnicos em liberar os mesmos para atividades de formação.

Essa constatação reforça a necessidade de programas de formação específicos e dirigidos para as diferentes unidades da federação, que poderiam ser operacionalizados na modalidade presencial, ou semipresencial, considerando a metodologia do sociodrama como mecanismo facilitador desse processo de formação. Concomitantemente, é preciso repensar a estrutura didática e pedagógica dos cursos de formação voltados para "ação" dos agentes públicos em casos de desastres naturais.

Com relação ao item "g" descrito acima, o resultado da sondagem inicial foi o seguinte: a) no que se refere às preferências de formação, $62 \%$ dos entrevistados optaram pela área de prevenção de desastres naturais. Com relação aos demais temas de interesse, seguem por ordem de importância: prevenção de desastres (86\%); preparação para desastres (86\%); respostas aos desastres (70\%); redução de riscos de desastres de forma transversal (45\%), e recuperação (30\%). Entretanto, no contexto geral, a redução de riscos de desastres, tem sido a área prioritária com $40 \%$ de aderência dos entrevistados.

Pelos dados apresentados, verifica-se que a prevenção e a preparação apresentaram os maiores percentuais, caracterizando sobremaneira, a necessidade dos agentes públicos em estarem aptos para o exercício de suas atividades de natureza operacional. 
Os resultados das entrevistas acabaram por aprofundar as questões já identificadas na sondagem inicial, tais como, questões relativas ao "gênero" para populações vulneráveis, à baixa qualidade, a falta de opções e os resultados práticos dos cursos de formação em gestão de riscos e de desastres.

As questões descritas no parágrafo anterior, ainda precisam ser trabalhadas de forma mais intensiva por metodologias de ação, já que se trata de intervenções com comunidades em áreas de risco.

Até aqui foram apresentados os resultados do diagnóstico relativo às necessidades de formação em gestão de riscos e de desastres no Brasil. Nessa perspectiva, urge estabelecer o nexo de causalidade entre as demandas de necessidades de formação, com toda a estrutura organizacional das instituições, que tem por competência e atribuição alguma atividade relacionada à proteção e defesa civil.

$\mathrm{Na}$ Tabela I, aparecem os resultados das demandas por Estado da federação dos tipos de processos de formação, que poderiam ser desenvolvidos a partir do sociodrama como método de ensino.

A adoção do sociodrama organizacional com técnicas e jogos psicodramáticos se constitui num instrumento de identificação dos gaps que poderão ser utilizados para reorientação de processos de formação e "mobilização para ação" dos agentes públicos.

A partir da compreensão socionômica, não se poderá chegar a sociatria, sem antes, ter uma compreensão fenomenológica da sociodinâmica, bem como, do modo como a rede sociométrica relacionada à gestão de riscos e de desastres naturais está organizada. O diagnóstico organizacional a partir de técnicas psicodramáticas associados ao sociodrama tornarão possíveis que se consiga estabelecer um programa de formação em gestão de riscos e de desastres com controle de resultados, ao mesmo tempo em que se levanta através da metodologia em questão, o que deve ser meIhorado operacionalmente em cada agente público, mobilizando-o para a ação, reorientando proposições de controle de resultados, monitoramento das atividades de gestão de riscos e de desastres, dentro de seu contexto institucional. Com isso, pode-se inferir que num primeiro momento serão identificados diferentes níveis de desenvolvimento da matriz de identidade institucional das instituições relacionadas que possuem atribuições e competência relacionada à gestão de riscos e de desastres naturais (Tabela 1). 


\begin{tabular}{|c|c|c|c|}
\hline Tipo & Tema & $\begin{array}{l}\text { Nível Territorial } \\
\text { Prioritário }\end{array}$ & $\%$ \\
\hline \multirow[t]{4}{*}{ Básico } & $\begin{array}{l}\text { Atualização dos conhecimentos em } \\
\text { gestão de risco de desastres }\end{array}$ & $\begin{array}{l}\text { Regional, estadual, mu- } \\
\text { nicipal e comunitário. }\end{array}$ & 24,5 \\
\hline & $\begin{array}{c}\text { Conhecimento da Proteção e da } \\
\text { Defesa Civil }\end{array}$ & & \\
\hline & $\begin{array}{c}\text { Gestão de Projetos (geral e aplicado } \\
\text { aos Desastres) }\end{array}$ & $\begin{array}{l}\text { Regional, estadual, mu- } \\
\text { nicipal e comunitário. }\end{array}$ & 11,5 \\
\hline & $\begin{array}{l}\text { Gestão de Risco de Desastres den- } \\
\text { tro da Proteção e da Defesa Civil }\end{array}$ & & \\
\hline \multirow[t]{4}{*}{ Avançado } & $\begin{array}{l}\text { Prevenção e Mitigação (Gestão } \\
\text { Preventiva de Desastres) }\end{array}$ & $\begin{array}{l}\text { Regional, estadual, mu- } \\
\text { nicipal e comunitário. }\end{array}$ & 11,3 \\
\hline & Preparação e Resposta & $\begin{array}{c}\text { Regional, estadual, } \\
\text { municipal. }\end{array}$ & 8,5 \\
\hline & $\begin{array}{l}\text { Curso de conhecimento de risco } \\
\text { nível local }\end{array}$ & $\begin{array}{l}\text { Regional, estadual, mu- } \\
\text { nicipal e comunitário. }\end{array}$ & 18,5 \\
\hline & Recuperação & $\begin{array}{l}\text { Regional, estadual, } \\
\text { municipal. }\end{array}$ & 5,7 \\
\hline \multicolumn{4}{|l|}{ Especializado } \\
\hline & Prevenção na Empresa & $\begin{array}{l}\text { Regional, estadual, } \\
\text { municipal. }\end{array}$ & 0,8 \\
\hline & $\begin{array}{l}\text { Curso de Gestão de Riscos e Desas- } \\
\text { tres para Gestores Comunitários }\end{array}$ & $\begin{array}{c}\text { Regional, estadual, } \\
\text { municipal. }\end{array}$ & 4,2 \\
\hline & $\begin{array}{c}\text { Comunicação, sensibilização e } \\
\text { articulação. }\end{array}$ & $\begin{array}{l}\text { Municipal e Comuni- } \\
\text { tário }\end{array}$ & 6,8 \\
\hline & $\begin{array}{l}\text { Doutorado ou Pós Graduação em } \\
\text { Proteção e Defesa Civil (Gestão da } \\
\text { Defesa Civil) }\end{array}$ & $\begin{array}{l}\text { Regional, estadual, mu- } \\
\text { nicipal e comunitário. }\end{array}$ & 1,8 \\
\hline & $\begin{array}{c}\text { Sensibilização sobre Proteção e } \\
\text { defesa Civil em Escolas Primárias } \\
\text { Secundárias }\end{array}$ & $\begin{array}{l}\text { Regional, estadual, e } \\
\text { comunitário. }\end{array}$ & 1,1 \\
\hline & Formação de Formadores & $\begin{array}{l}\text { Regional, estadual, mu- } \\
\text { nicipal e comunitário. }\end{array}$ & 3,3 \\
\hline
\end{tabular}

Tabela 1 - Prioridades de Formação ao Nível Territorial por Estados.

Fonte: Diagnóstico e Análise das Necessidades de Demandas de Formação em Gestão de Risco e de Desastres. Projeto BRA12/2017. 2017, p.161.

Por outro lado, a diferenciação desses níveis de desenvolvimento é que deverá ser considerada, tendo como objetivo atingir uma meta de integração, num processo de planejamento de médio em longo prazo para atingir seus objetivos finais.

Convém ressaltar que as diferentes etapas da matriz de identidade institucional serão identificadas concomitantemente, pelo diagnóstico organizacional, a partir de técnicas psicodramáticas e sociométricas. As atividades serão desenvolvidas com os agentes 
públicos das diferentes instituições envolvidas na gestão de riscos e de desastres naturais do Brasil.

Nesse contexto, somente "conhecimentos técnicos" não mobilizarão os agentes públicos para a "ação" num evento extremo. Com isso se está querendo afirmar, que se os agentes públicos não vão para a ação é porque sua espontaneidade, criatividade e sensibilidade não estão mobilizadas para agir, a partir do reconhecimento das estruturas das referidas instituições. Em parte, atividades práticas orientadas para mobilização para ação, em processos de formação para gestão de riscos e de desastres naturais devem ter por princípio, a libertação dos gatilhos da espontaneidade, criatividade e sensibilidade de cada agente público que, impedido por questões diversas, acaba não se mobilizando para a ação.

Tal resultado é tão claro, que os cursos teóricos já desenvolvidos no Brasil sobre gestão de riscos e de desastres naturais, não mobilizaram os mesmos para a ação em eventos extremos.

É importante verificar que o escopo desse diagnóstico não era organizacional, mas identificar necessidades de demandas de formação. Pela lógica, os autores alertam que novamente um equívoco metodológico foi cometido na condução dessa pesquisa ao se desconsiderar o diagnóstico organizacional, como base para sustentação posterior das demandas dos processos de formação em gestão de riscos e de desastres naturais.

Essa lacuna, ainda atual e presente, será resolvida se a proposição desse artigo se constituir numa ação nacional de intervenção para tornar possível que agentes públicos estejam capacitados para se mobilizarem para a ação em situações de riscos e de desastres ambientais.

A partir desse diagnóstico, já se tem um conjunto de ocorrências passíveis de investigação, com vistas à caracterização de um diagnóstico organizacional, a partir do sociodrama, utilizando técnicas psicodramáticas. Tendo um diagnóstico organizacional, fundamentado na socionomia e o sociodrama como metodologia de intervenção, será possível considerar a espontaneidade de cada grupo de agentes públicos como recurso para mobilização em caso de eventos extremos.

A integração de todas as discussões realizadas anteriormente 
tornará possível que, ao final, sejam propostas diretrizes para, num futuro próximo, se constituir um "programa nacional de mobilização para ação dos agentes públicos, orientados para desastres naturais".

\section{A SOCIONOMIA DOS DESASTRES NATURAIS}

\section{A Sociodinâmica, A Sociatria e a Sociometria na Gestão de Riscos e de Desastres Naturais.}

A socionomia enquanto forma de compreensão dos desastres naturais, envolve questões que transcendem o diagnóstico organizacional, a partir da realização de sociodrama. Entretanto, o diferencial da fundamentação socionômica é que seu criador Moreno (1975) integrou a análise das relações sociais (sociodinâmica), a análise dos conflitos sociais (sociometria), e técnicas de intervenção terapêuticas visando o resgate da saúde em indivíduos e grupos (sociatria).

Esta integração pode ser aplicada às instituições envolvidas na gestão de riscos e de desastres ambientais, onde a sociodinâmica dos diferentes grupos de agentes públicos envolvidos nessas atividades, por falta de reconhecimento de si e de grupos de outras instituições, em termos de atribuições e competências, acabam por promover conflitos, que deverão ser avaliados sociometricamente, conforme verificados por SILVA (2000). Esses conflitos são desdobrados em questões diversas que impedem o desenvolvimento da PNPDEC, São questões operacionais, políticas, financeiras e de gestão que exigem intervenções sociátricas para a redução de tensões intergrupais de diferentes instituições da gestão de riscos e dos desastres naturais.

O processo completo de verificação de um ato socionômico parte da compreensão da sociodinâmica das instituições que estão envolvidas na gestão de riscos e de desastres ambientais, na identificação dos conflitos decorrentes das competências comuns e concorrentes (sociometria), bem como, das demandas que deverão ser atendidas e resolvidas pelas diferentes instituições (sociatria). 
Há necessidade de verificar em que estágio do "desenvolvimento da matriz de identidade" ${ }^{10}$ estão os grupos de agentes públicos das diferentes instituições internamente, e posteriormente e externamente, os envolvidos na gestão de riscos e de desastres naturais.

O "encontro" seria a etapa em que a gestão tornaria possível o cumprimento da PNPDEC em sua plenitude e o reconhecimento da sociedade, das respectivas atribuições e responsabilidades constitucionais, no âmbito da gestão de riscos e de desastres naturais, numa condição de reconhecimento pelos grupos das diferentes instituições da inversão dos seus papéis funcionais.

Da mesma forma, a perspectiva de proteção e de defesa civil foi historicamente objeto de gestão de estruturas policiais militares e de inteligência, o que por si só, imprimiu no Brasil, uma sociodinâmica, onde a população não faz parte da gestão dos riscos e dos desastres.

Esse espaço de "empoderamento" ainda precisa ser construído tanto para as demais instituições envolvidas, como para que as ações e mobilizações populares e institucionais sejam cada vez mais efetivas.

Diante das consequências decorrentes não só das mudanças climáticas, mas também da intervenção humana sobre o espaço geográfico, a socionomia e o sociodrama como fundamentos e método de intervenção, tem o potencial de se constituir num recurso de investigação, intervenção, avaliação e inovação para gestão de riscos e de desastres naturais.

\section{A Teoria da Matriz de Identidade dos Grupos das Diferentes Instituições da PNPDEC.}

No contexto da socionomia, a teoria da matriz de identidade se constitui num dos núcleos de sustentação analítica do psicodrama e do sociodrama, nosso objeto de investigação. Vários autores têm desenvolvido compreensões acerca da matriz de identidade para indivíduos e grupos, dentre os quais, podemos citar: DATNER (2006), FONSECA FILHO (1980) e MORENO (1975). Para explicitação

10 A teoria do desenvolvimento da matriz de identidade descreve as etapas do desenvolvimento institucional. 
das etapas, utilizaremos a proposta ampliada de FONSECA FILHO (1980) que subdivide a Teoria da Matriz de Identidade em 10 etapas, conforme descrita na Figura 2, a seguir.
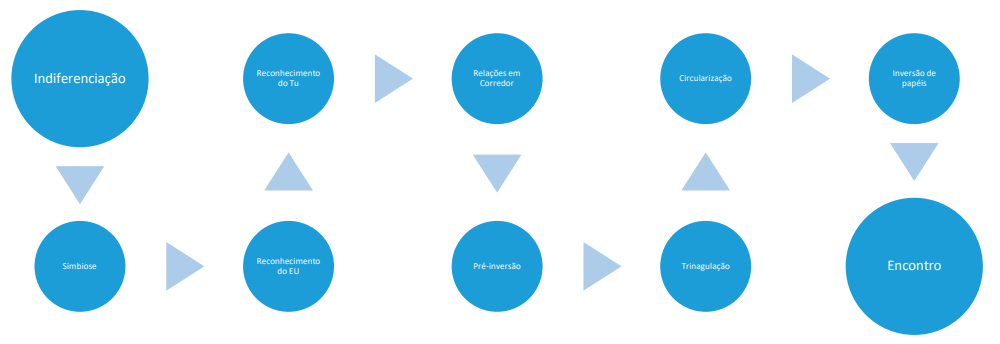

Figura 2. Etapas da Matriz de Identidade

Fonte: Construção dos autores, 2017.

No âmbito da teoria da matriz de identidade, relacionada aos grupos das instituições envolvidas com gestão de riscos e desastres naturais, temos a considerar:

a) na fase de "indiferenciação", os grupos das instituições ainda não conseguem ter a dimensão de suas atribuições ou competências internas e, muito menos, da existência de outras instituições que possuem atribuições e competências comuns que poderiam ser integradas, melhorando sensivelmente o processo de gestão de riscos e de desastres. Inicia logo após a formação dos grupos e está caracterizada por relações "caóticas e indiferenciadas";

b) na fase de "simbiose", os grupos estão, dentro das respectivas instituições, em processo de formação de sua identidade totalmente dependentes da instituição e/ou de alguém da instituição;

c) na terceira fase de "reconhecimento de si mesmo", os grupos começam a ter uma dimensão de quem são, de como estão constituídos, seus objetivos, forças e fragilidades, da estrutura da instituição e de seus papéis funcionais e profissionais;

d) Na quarta fase, os grupos começam a verificar que existe uma missão, visão e objetivos a perseguir, e que as instituições nem sempre estão voltadas para satisfazer os papéis funcionais de agentes públicos, ou sejam buscam reconhecer a instituição a que pertencem de forma apropriada; 
e) Na quinta fase chamada de "relações em corredor", os grupos passam a ter uma representação do outro, que nem sempre está relacionado ao seu verdadeiro status. Ao se vincular a outro grupo, exemplo ao grupo "b" recusam socializar com outros grupos ("c", "d", etc.). Podem surgir estereótipos de um grupo de uma instituição em relação as demais devido às representações, bem como comportamentos de competição e rivalização ao invés de colaboração. Quando existe a relação intergrupal está baseada em duplas ou parcerias;

f) Na sexta fase chamada de 'pré-inversão', os grupos começam a ter um primeiro contato entre si, com as suas condicionantes, deficiências e potencialidades, sem que isso represente um reconhecimento recíproco, que justifique uma relação de cooperação direta;

g) Na sétima fase, chamada de "triangulação", começa o estabelecimento da relação entre grupos de diferentes instituições ampliando o seu campo de relações através das competências comuns e concorrentes. Superada esta etapa o grupo está apto a lidar com exclusões;

h) Na oitava fase conhecida como "circularização", os grupos das diferentes instituições passam a estabelecer relações funcionais saindo de relacionamentos de sua própria esfera, para todas as esferas de atuação, sejam elas, na escala municipal, estadual e federal;

i) A nona etapa é denominada de "inversão de papéis". Nessa etapa os grupos possuem a habilidade de integração intersetorial, com grupos de todas as instituições, permitindo o estabelecimento de relações mútuas e de reciprocidade, prevalecendo à cooperação, conforme objetivo da PNPDEC;

j) Na décima fase, tem-se o "encontro", ou seja, o reconhecimento mútuo entre os grupos das diferentes competências comuns e concorrentes. É a etapa onde ocorre a expressão máxima do "nós". Neste amplo espaço de cooperação haverá o desenvolvimento pleno da PNPDEC.

A PNPDEC, em sua estrutura que dispõe sobre a integração das políticas de ordenamento territorial, desenvolvimento urbano, saúde, meio ambiente, mudanças climáticas, gestão de recursos hídricos, geologia, infraestrutura, educação, ciência e tecnologia e 
às demais políticas setoriais, buscando a promoção do desenvolvimento sustentável, está acentuando a necessidade de um esforço institucional que deverá ser realizado pelas instituições envolvidas na gestão de riscos e de desastres naturais.

O Diagnóstico Organizacional, com base no Sociodrama, identificará, dentre as 10 (dez) etapas descritas, em quais estão enquadradas os diferentes grupos institucionais e, a partir dessa constatação, realizará ações para que a última etapa da matriz de identidade das instituições chegue progressivamente num patamar, onde a PNPDEC esteja completamente implantada e reconhecida, não só pelas instituições e seus respectivos grupos, como também pela população de uma maneira geral.

\section{O Sociodrama Organizacional Aplicado às Instituições vinculadas a Proteção e Defesa Civil no Brasil}

O Sociodrama como método de intervenção para grupos, no âmbito do psicodrama é um recurso não só terapêutico, mas também de diagnóstico dos grupos de agentes públicos envolvidos na gestão de riscos e de desastres naturais.

Diferentemente do "psicodrama de grupo"11 e do "psicodrama em grupo"12, que trabalha com temáticas grupais privativas, o Sociodrama desenvolve atividades socioterapêutica com temáticas institucionais e externas aos grupos, no caso em questão, a gestão de riscos e de desastres naturais relacionadas às diferentes instituições, onde os diversos grupos de agentes públicos estão lotados para desenvolvimento de papeis funcionais relativos a essas atividades. A adoção de técnicas já consagradas no âmbito da Socionomia, a serem aplicadas nesse caso, tornarão possíveis que num ambiente de espontaneidade, criatividade e sensibilidade às demandas não identificadas pelo SEDEC/PNUD (2014) apareçam sem defesas, tornando possível verificar os impedimentos dos referidos grupos e de suas capacidades, não só de conhecimento, como também, de mobilização para ação em situação de desastres

11 O psicodrama de grupo tem por objetivos, o processo terapêutico de uma demanda interna do grupo;

12 O psicodrama em grupo tem por objetivos, o processo terapêutico de uma demanda interna de alguém do grupo; 
naturais. A realização de Sociodramas organizacionais deverá ter uma dinâmica que se iniciará por grupos de agentes públicos municipais, estaduais e nacionais, em franco processo de integração, para fins de identificação dos gaps relativos às estruturas para gestão de riscos e de desastres naturais.

A prática da aplicação do Sociodrama envolve demarcação dos contextos a serem tomados para fins de intervenção, dos instrumentos e das etapas do mesmo. Em linhas gerais, os contextos a serem considerados para o desenvolvimento dos sociodramas são: social ${ }^{13}$, grupal ${ }^{14}$ e psicodramático ${ }^{15}$. Concomitantemente, deverão ser aplicadas, a cada passo, técnicas adequadas à etapa de desenvolvimento da matriz de identidade de cada grupo ou ao conjunto das instituições envolvidas nos sociodramas a serem realizados.

Para que o sociodrama se configure metodologicamente como atividade de diagnóstico organizacional é necessário estabelecer os seguintes instrumentos: cenário ${ }^{16}$, protagonista ${ }^{17}$, diretor ${ }^{18}$, egos auxiliares ${ }^{19}$ e público ${ }^{20}$. Da mesma forma, as etapas a serem desenvolvidas são: aquecimento inespecífico ${ }^{21}$, aquecimento específico ${ }^{22}$, dramatização ${ }^{23}$, compartilhamento ${ }^{24}$, e processamento ${ }^{25}$. O processamento técnico, não será conjunto com os grupos envolvidos

130 contexto social é aquele em ocorre a sociodinâmica objeto de investigação do sociodrama;

14 O contexto grupal é aquele referente a um grupo numa sociodinâmica externa dada;

150 contexto psicodramático é aquele onde o impossível e o inimaginável pode ocorrer de modo catártico;

16 O cenário é o local onde se realiza o sociodrama;

17 O protagonista no sociodrama é o tema que mobilizará o grupo para a dramatização;

18 O diretor é aquele que conduz a sessão de sociodrama;

19 Os egos auxiliares são agentes coadjuvantes do diretor e dos agentes dos temas protagônicos.

20 O público é quem participa do processo;

21 A etapa do aquecimento inespecífico é aquela em que o grupo começa a ser preparado para a ação;

22 A etapa do aquecimento específico é aquele em que o tema protagônico está definido;

23 A etapa da dramatização é aquela em que ocorre a resolução do tema com a representação dos agentes sociais ausentes;

24 A etapa do compartilhamento é aquela em que os membros do grupo compartilham a sua experiência;

25 A etapa do processamento é aquele em que o diretor é avaliado na sua atuação no sociodrama. 
no sociodrama e ocorrerá exclusivamente com a equipe técnica envolvida no processo, sendo de extrema utilidade para corrigir desconformidades do processo diagnóstico e produção do relatórios parciais e final dos sociodramas realizados. Será necessário distinguir 'narração' de 'processamento técnico de condução', em todo o processo o processamento será pautado no protocolo já consagrado de KELLERMANN (1998). Da mesma forma, as técnicas clássicas do sociodrama, tais como, Espelho, Duplo, Inversão de Papéis, Solilóquio, Interpolação de Resistência, Role-Playing, Teatro Espontâneo, Axiodrama, Playback Teatro, Concretização, Maximização, Imagem, Cinedrama, Videodrama, Sociograma, Bibliodrama, Teatro de Reprise, Sociodrama Público, Auto-dirigido, Jornal Vivo, poderão ser acrescidas de Jogos Dramáticos que potencializarão a ação dos agentes públicos a se mobilizarem para identificar ações a serem desenvolvidas em situação de desastres naturais. Se o relatório do SEDEC/PNUD detectou que a mobilização para ação e o caráter técnico e teórico dos processos de formação, não atingiram os objetivos, não se poderia, portanto, propor uma saída dentro dos mesmos requisitos que deram origem ao problema em discussão. Por isso, para a mobilização dos agentes públicos para a ação, nada melhor que utilizar o sociodrama que tem na "ação" sua maior característica de diagnóstico organizacional. Por questões de cultura organizacional, relações sociométricas assimétricas já estabelecidas, muitas vezes ainda não estão prontas para acionamento, o que impede de reconhecer efetivamente o que mobilizaria os agentes públicos para a ação, através de outros recursos que não conseguem identificar essas variáveis.

O que não aparece numa entrevista cercada de perguntas racionais sustentadas por mecanismos de defesa e que mobiliza apenas a cognição do sujeito, aparece espontaneamente num diagnóstico organizacional fundamentado num sociodrama que mobiliza o pensar-sentir-agir simultaneamente. Eis a potencialidade do sociodrama como recurso de mobilização para ação.

Entretanto, através do diagnóstico organizacional a partir do sociodrama, dar-se-ia o primeiro passo concreto para o reconhecimento tanto das demandas de necessidades de formação e suas características pelos agentes públicos, bem como, se após terem sido capacitados, como deverão integrar o que aprenderam, na 
estrutura organizacional dos quais são parte, e, em que medida, com a estrutura existente, fazerem algo que atenda o que prevê a Política Nacional de Proteção e Defesa Civil, os protocolos, as estratégias e marcos, já descritos.

A partir da Tabela 2 pode-se verificar a complexidade para se efetivar a PNPDEC no Brasil, considerando os 16 (objetivos) gerais da referida legislação, e sua relação com os 7 (sete) resultados da sondagem verificados através de pesquisa realizada pelo SEDEC/ PNUD (2014).

Pode-se constatar que para cada objetivo, deverá ser desenvolvido:

- No âmbito interno de cada instituição a realização de sociodrama relacionado com cada um dos objetivos, e sua relação com as competências de escala espacial (União, Estado e Municípios) e setorial (Instituições com Políticas Públicas vinculadas), em relação às 7 (sete) não conformidades identificadas;

- No âmbito interinstitucional deverá ser realizado sociodrama para redução/eliminação de conflitos de competência comum e concorrente;

- Após a identificação do estágio da matriz de identidade do âmbito institucional e interinstitucional é que se poderão propor intervenções sociátricas 


\begin{tabular}{|c|c|c|c|c|c|c|c|}
\hline Resultados da Sondagem/ Objetivos da PNDEC & $\begin{array}{l}\text { Familiaridade com a } \\
\text { Lei } 12.608 / 2012 \mathrm{e} \\
\text { SINPDEC }\end{array}$ & $\begin{array}{l}\text { Conhecimento e } \\
\text { capacidade para a } \\
\text { articulação } \\
\text { interinstitucional } \\
\text { (vertical e horizontal); }\end{array}$ & $\begin{array}{l}\text { Determinação de riscos e } \\
\text { formulação de medidas } \\
\text { para redução de riscos no } \\
\text { seu município e Estado }\end{array}$ & $\begin{array}{l}\text { Capacidades técnicas } \\
\text { nas etapas da } \\
\text { proteção e defesa } \\
\text { civil, }\end{array}$ & $\begin{array}{l}\text { Nivel de cobertura } \\
\text { temática do processo } \\
\text { de formação por } \\
\text { Estado }\end{array}$ & $\begin{array}{l}\text { Niveis de acesso às } \\
\text { informações sobre } \\
\text { proteção e defesa } \\
\text { civil }\end{array}$ & $\begin{array}{l}\text { Necessidade de } \\
\text { formação em } \\
\text { proteção e defesa } \\
\text { civil. }\end{array}$ \\
\hline Reduzir os riscos de desastres & $\mathrm{x}$ & $\mathrm{x}$ & $\mathrm{x}$ & $\mathrm{x}$ & $\mathrm{x}$ & $\mathrm{x}$ & $\mathrm{x}$ \\
\hline $\begin{array}{l}\text { Prestar socorro e assistência às populações } \\
\text { atingidas nos desastres }\end{array}$ & $\mathrm{x}$ & $\mathrm{x}$ & $\mathrm{x}$ & $\mathrm{x}$ & $\mathrm{x}$ & $\mathrm{x}$ & $\mathrm{x}$ \\
\hline Recuperar as áreas afetadas por desastres & $\mathrm{x}$ & $\mathrm{x}$ & $\mathrm{x}$ & $\mathrm{x}$ & $\mathrm{x}$ & $\mathrm{x}$ & $\mathrm{x}$ \\
\hline $\begin{array}{l}\text { Incorporar a redução do risco de desastre e as } \\
\text { açōes de proteção e defesa civil entre os } \\
\text { elementos da gestão territorial e do } \\
\text { planejamento das políticas setoriais }\end{array}$ & $\mathrm{x}$ & $\mathrm{x}$ & $\mathrm{x}$ & $\mathrm{x}$ & $\mathrm{x}$ & $\mathrm{x}$ & $\mathrm{x}$ \\
\hline $\begin{array}{l}\text { Promover a continuidade das ações de proteção } \\
\text { e defesa civil }\end{array}$ & $\mathrm{x}$ & $\mathrm{x}$ & $\mathrm{x}$ & $\mathrm{x}$ & $\mathrm{x}$ & $\mathrm{x}$ & $\mathrm{x}$ \\
\hline $\begin{array}{l}\text { Estimular o desenvolvimento de cidades } \\
\text { resilientes e os processos sustentáveis de } \\
\text { urbanização }\end{array}$ & $\mathrm{x}$ & $\mathrm{x}$ & $\mathrm{x}$ & $\mathrm{x}$ & $\mathrm{x}$ & $\mathrm{x}$ & $\mathrm{x}$ \\
\hline $\begin{array}{l}\text { Promover a identificacacão e avaliação das } \\
\text { ameaças, suscetibilidades evulnerabilidades a } \\
\text { desastres, de modo a evitar ou reduzir sua } \\
\text { ocorrência. }\end{array}$ & $\mathrm{x}$ & $\mathrm{x}$ & $\mathrm{x}$ & $\mathrm{x}$ & $\mathrm{x}$ & $\mathrm{x}$ & $\mathrm{x}$ \\
\hline $\begin{array}{l}\text { Monitorar os eventos meteorológicos, } \\
\text { hidrológicos, geológicos, biológicos, nucleares, } \\
\text { químicos e outros potencialmente causadores de } \\
\text { desastres. }\end{array}$ & $\mathrm{x}$ & $x$ & $\mathrm{x}$ & $\mathrm{x}$ & $\mathrm{x}$ & $\mathrm{x}$ & $\mathrm{x}$ \\
\hline $\begin{array}{l}\text { Monitorar os eventos meteorológicos, } \\
\text { hidrológicos, geológicos, biológicos, nucleares, } \\
\text { químicos e outros potencialmente causadores de } \\
\text { desastres. }\end{array}$ & $\mathrm{x}$ & $\mathrm{x}$ & $x$ & $\mathrm{x}$ & $\mathrm{x}$ & $\mathrm{x}$ & $\mathrm{x}$ \\
\hline $\begin{array}{l}\text { Produzir alertas antecipados sobre a } \\
\text { possibilidade de ocorrência de desastres } \\
\text { naturais }\end{array}$ & $\mathrm{x}$ & $\mathrm{x}$ & $\mathrm{x}$ & $\mathrm{x}$ & $\mathrm{x}$ & $\mathrm{x}$ & $\mathrm{x}$ \\
\hline $\begin{array}{l}\text { Estimular o ordenamento da ocupação do solo } \\
\text { urbano e rural, tendo em vista sua conservação } \\
\text { e a proteção da vegetação nativa, dos recursos } \\
\text { hídricos e da vida humana. }\end{array}$ & $\mathrm{x}$ & $x$ & $\mathrm{x}$ & $x$ & $x$ & $x$ & $x$ \\
\hline $\begin{array}{l}\text { Combater a ocupação de áreas ambientalmente } \\
\text { vulneráveis e de risco e promover a realocação } \\
\text { da população residente nessas áreas }\end{array}$ & $\mathrm{x}$ & $\mathrm{x}$ & $\mathrm{x}$ & $\mathrm{x}$ & $x$ & $x$ & $x$ \\
\hline $\begin{array}{l}\text { Estimular iniciativas que resultem na destinação } \\
\text { de moradia em local seguro }\end{array}$ & $\mathrm{x}$ & $\mathrm{x}$ & $\mathrm{x}$ & $\mathrm{x}$ & $\mathrm{x}$ & $\mathrm{x}$ & $\mathrm{x}$ \\
\hline $\begin{array}{l}\text { Desenvolver consciência nacional acerca dos } \\
\text { riscos de desastres }\end{array}$ & $\mathrm{x}$ & $\mathrm{x}$ & $\mathrm{x}$ & $\mathrm{x}$ & $\mathrm{x}$ & $\mathrm{x}$ & $\mathrm{x}$ \\
\hline $\begin{array}{l}\text { Orientar as comunidades a adotar } \\
\text { comportamentos adequados de prevenção e de } \\
\text { resposta em situação de desastre e promover a } \\
\text { autoproteção; }\end{array}$ & $\mathrm{x}$ & $\mathrm{x}$ & $\mathrm{x}$ & $\mathrm{x}$ & $\mathrm{x}$ & $\mathrm{x}$ & $x$ \\
\hline $\begin{array}{l}\text { Integrar informações em sistema capaz de } \\
\text { subsidiar os órgãos do SINPDEC na previsão e no } \\
\text { controle dos efeitos negativos de eventos } \\
\text { adversos sobre a população, os bens e serviços e } \\
\text { o meio ambiente. }\end{array}$ & $\mathbf{x}$ & $x$ & $x$ & $x$ & $x$ & $x$ & $x$ \\
\hline
\end{tabular}

Tabela 2. Níveis de Relação entre os Resultados da Sondagem x Objetivos da PNPDEC.

Fonte: Construção dos autores, 2017. 
Assim, seriam necessários 112 (cento e doze) sociodramas temáticos institucionais, e 112 (cento e doze) sociodramas interinstitucionais para se conseguir todos os requisitos relativos à plena institucionalização da PNPDEC. Após a realização dos 224 (duzentos e vinte quatro) sociodramas temático institucional é possível ter uma compreensão cientifica passível de intervenção com consequência e controle de resultados, para execução da PNPDEC.

Nessa mesma perspectiva, todos os resultados das avaliações poderiam se constituir numa proposta de planejamento de longo prazo, conforme modelo do "Projeto Brasil 3 Tempos", iniciado no Brasil no ano de 2004.

Por sua vez, o cumprimento de fazer, tanto da instituição pública, quanto do agente público deverá ser colocado no nível de responsabilidade de suas atribuições, com vistas à redução de riscos e de desastres ambientais no país.

\section{DIRETRIZES PARA DESENVOLVIMENTO DE INTEGRAÇÃO DE AÇÕES DE PROTEÇÃO E DEFESA CIVIL NO BRASIL, A PARTIR DE SOCIODRAMAS ORGANIZACIONAIS TEMÁTICOS.}

A partir da tabela II é verificado que todos os objetivos da PNPDEC estão por serem reconhecidas pelas diferentes "Instituições em si" e "entre si", nas diferentes escalas espaciais de atuação.

Esses resultados caracterizam o estado atual das Instituições da Proteção e Defesa Civil, na fase da matriz de identidade, ou seja, a necessidade do reconhecimento de si mesmas, diante do conjunto de instituições que envolvem o Sistema Nacional de Proteção e Defesa Civil - SINPDEC, para a efetiva institucionalização da PNPDEC no Brasil.

Com base nas discussões e proposições descritas anteriormente, os autores propõem um conjunto de diretrizes que poderão ser objeto de um "Projeto Nacional de Institucionalização da Proteção e da defesa Civil". 


\section{Estágios das Diretrizes}

A seguir serão descritos estágios de desenvolvimento da Matriz de Identidade Institucional para Gestão dos Riscos e de Desastres, bem como, as diretrizes que deverão ser desenvolvidas, a partir de sociodramas, como recurso para diagnóstico organizacional, das instituições envolvidas na gestão de riscos e de desastres ambientais no Brasil.

\section{Estágio 1 - Inexistência Total de Reconhecimento Interno da Instituição}

"Diretriz 1: Desenvolver diagnóstico organizacional a partir de sociodrama, que apliquem técnicas de 'reconhecimento dos grupos, no âmbito interno das instituições", envolvidas com gestão de riscos e de desastres naturais.

\section{Estágio 2 - Existência de Reconhecimento de Si e das Outras Instituições}

Diretriz 2: Desenvolver diagnóstico organizacional a partir de sociodrama, que apliquem técnicas de "reconhecimento dos grupos e de outras instituições, no âmbito interno das instituições" envolvidas com gestão de riscos e de desastres naturais.

\section{Estágio 3-Reconhecimento de si mesmo Institucional;}

Diretriz 3: Desenvolver diagnóstico organizacional a partir de sociodrama, que apliquem técnicas de "reconhecimento dos grupos, e dos seus papéis funcionais e profissionais" relativos à gestão de riscos e desastres naturais.

\section{Estágio 4 - Reconhecimento das Outras Instituições;}

Diretriz 4: Desenvolver diagnóstico organizacional a partir de sociodrama, que apliquem técnicas para "reconhecimento pelos grupos da missão, visão e objetivos internos papéis funcionais", em relação aos papéis profissionais relativos à gestão de riscos e desastres naturais.

\section{Estágio 5 - Relações em Corredor;}

Diretriz 5: Desenvolver diagnóstico organizacional a partir de sociodrama, que apliquem técnicas de "reconhecimento dos grupos internos com grupos de outras instituições, com o objetivo de caracterizar os diferentes desejos e projetos funcionais e profissionais' relativos à gestão de riscos e desastres naturais". 


\section{Estágio 6 - Pré-inversão}

Diretriz 6: Desenvolver diagnóstico organizacional a partir de sociodrama, que apliquem técnicas para "reconhecimento dos grupos internos com grupos de outras instituições, com o objetivo de caracterizar as diferentes competências comuns e concorrentes através dos diferentes papéis funcionais e profissionais'".

\section{Estágio 7 - Triangulação}

Diretriz 7: Desenvolver diagnóstico organizacional a partir de sociodrama, que apliquem técnicas de relação funcional e de "reconhecimento dos grupos internos"' com grupos de outras instituições, com o objetivo de caracterizar os diferentes níveis de complementariedade de suas diferentes competências comuns e concorrentes através dos diferentes papéis funcionais e profissionais'.

\section{Estágio 8 - Circularização}

Diretriz 7: Desenvolver diagnóstico organizacional a partir de sociodrama, que apliquem técnicas de reconhecimento dos grupos internos com grupos de outras instituições, em diferentes escalas espaciais com o objetivo de caracterizar os diferentes níveis de complementariedade de suas diferentes competências comuns e concorrentes através dos diferentes papéis funcionais e profissionais'.

\section{Estágio 9 - Inversão de Papéis}

Diretriz 9: Desenvolver diagnóstico organizacional a partir de sociodrama, que apliquem técnicas de reconhecimento dos grupos internos com grupos de outras instituições, visando integração intersetorial e reconhecimento mútuo, tanto técnico quanto operacional, da estrutura das competências comuns e concorrentes em proteção e defesa civil.

\section{Estágio 10 - Encontro}

Diretriz 10: Desenvolver diagnóstico organizacional a partir de sociodrama, que apliquem técnicas de reforço do reconhecimento mútuo, entre os grupos internos com grupos de outras instituições, com o objetivo de caracterizar e criar mobilização para ação, entre os diferentes agentes públicos das instituições, mobilizando-os para a ação em situação de desastres naturais.

A partir das diretrizes propostas, infere-se a necessidade de:

a) criar um movimento nacional visando o desenvolvimento de planos, programas e projetos específicos de "formação" a partir de um processo progressivo de reconhecimento do 
estágio do desenvolvimento da matriz de identidade das instituições envolvidas com a gestão de riscos e de desastres naturais;

b) Formar profissionais e envolvidos em situações de desastres naturais, a partir da mobilização para ação como eixo fundamental;

c) Tornar possível o empowerment tanto da população, quanto dos agentes públicos de suas reais capacidades de ação conjunta em situação de desastres naturais;

c) Caracterizar o sociodrama como recurso de investigação, intervenção, avaliação e inovação para fins de reconhecimento através dos instrumentos, etapas e contextos de não conformidades, que outros fundamentos e metodologias, que não tem a espontaneidade como variável não identificada, até o presente momento.

No âmbito das discussões se torna necessário que se os agentes públicos repensem a necessidade de que a ausência de processos de gestão poderá ocasionar, numa situação de um evento extremo, pela ausência completa de institucionalização da PNPDEC.

Nessa perspectiva, a avaliação da "capacidade de suporte das instituições envolvidas na gestão de riscos e de desastres naturais", identificada a partir do diagnóstico organizacional, através dos sociodramas temáticos, caracterização de modo efetivo, minimizará a precariedade da institucionalização da referida politica no Brasil.

\section{CONSIDERAÇÕES FINAIS}

Todo processo quando se inicia seja ele no âmbito da socialização, da produção do conhecimento, de uma mudança organizacional e/ou institucional, acaba por exigir do seu interlocutor a constituição de uma nova matriz de identidade relacional, de acordo com as novas exigências.

Os indivíduos, grupos, organizações e instituições estão em constante processo de desenvolvimento de sua matriz de identidade, bem como, vivendo a esperança de que novos encontros sejam possíveis, sejam eles: no âmbito do desempenho pessoal, profissional, institucional, de uma política pública reconhecida que gere uma nova resposta para questões até então sem perspectiva. 
Considerando as exigências, demandas de formação, inexistência de quadros técnicos para gestão de risco e de desastres nas prefeituras e Estados brasileiros torna-se necessário, repensar os resultados das políticas públicas, que devem estar desatreladas das competências federais, para que as populações e agentes públicos respectivos se empoderem da mesma, mobilizando-os para a ação.

A contribuição da Socionomia, com seu método sociodramático e sua Teoria do Desenvolvimento da Matriz de Identidade, como recurso para mapear o status atual das instituições públicas envolvidas na gestão de riscos e de desastres ambientais, se constitui num caminho pragmático para resolução das demandas ainda não atendidas constituindo no grande desafio para as referidas instituições e agentes públicos gestores dos processos operacionais.

Ao se utilizar recursos de ensino que não permitem o reconhecimento dos principais problemas que afetam a mobilização para a ação, não se conseguirá mobilizar agentes públicos para a ação.

O sociodrama, diferente dos métodos de intenção verbal e descritivo (entrevistas e questionários), torna possível a compreensão da verdadeira dimensão das dificuldades para mobilização e para a ação, por não trazer consigo mecanismos de defesas dos grupos.

Espera-se ter contribuído, a partir da discussão e diretrizes propostas, com um primeiro movimento para o fortalecimento da cultura de gestão de riscos e de desastres naturais, pois o Brasil merece.

\section{REFERÊNCIAS}

BRASIL. Ministério da Integração Nacional. Secretaria de Proteção e Defesa Civil. Diagnóstico e Análise das Necessidades de Formação em Gestão de Risco de Desastres: Projeto BRA 12/017 Fortalecimento da Cultura de Gestão de Risco de Desastres no Brasil. Brasília, 2014, 212 p.

BRASIL. Lei n. 12.608, de 10 de Abril de 2012. Institui a Política Nacional de Proteção e Defesa Civil - PNPDEC; dispõe sobre o Sistema Nacional de Proteção e Defesa Civil - SINPDEC e o Conselho Nacional de Proteção e Defesa Civil - CONPDEC; autoriza a criação de sistema de informações e monitoramento de desastres. Disponível em: http://www.planalto.gov.br/ccivil 03/ ato2011-2014/2012/lei/ I12608.htm, acesso em 16/04/2017.

DATNER, Yvette. Jogos para Educação Empresarial: jogos dramáticos role playing, jogos de empresa. São Paulo: Ágora, 2006. 
DOLABELLA, Rodrigo Paulo de Ulhôa. Informação e Contra Informação: a Guerra dos Cérebros. Belo Horizonte: Lastro EGL, 2009, 482p.

FONSECA FILHO, José de Souza. Psicodrama da Loucura: correlações entre Buber e Moreno. São Paulo: Ágora, 1980.

GONÇALVES, Camilla Salles et alii. Lições de Psicodrama: Introdução ao Pensamento de J.L. Moreno, São Paulo, Ágora, 1988.

KELLERMANN, Peter Felix. O Psicodrama em Foco. Tradução Eleny C. Keller. São Paulo: Ágora. 1988

MORENO, Jacob Levy. Psicodrama. Tradução de Álvaro Cabral. Editora Cultrix. São Paulo, 1975, 492p.

SILVA, Harrysson Luiz da. Avaliação Institucional de Prefeituras para Desenvolvimento de Projetos de Gestão Social. Instrucional Designer Márcia Loch - Palhoça: UNISUL Virtual, 2005. 127p.

. Paradiplomacia ambiental em regiões transfronteiriças. In: FRAGA, Nilson César (Org.). Territórios e Fronteiras: (re) arranjos e perspectivas. Florianópolis: Insular. 2011, 400p.

. Negociação e Conflitos: Livro Didático. Instrucional Designer Carolina Hoeller da Silva Boeing - Palhoça: UNISUL Virtual, 2006. 148p.

Conflitos e Negociação na Administração Pública Brasileira. Instrucional Designer Márcia Loch - Palhoça: UNISUL Virtual, 2005. 80p. , Gestão dos Conflitos Ambientais no Contexto da Convenção da Diversidade Biológica. In: PASA, Maria Corette (org.) Múltiplos Olhares sobre a Biodiversidade III. Jundiaí, Paco Editorial: 2014 360p.

. Tempística em Projetos. In: AVILA, Antonio Victorino, Jungles, Antonio Edésio. Gestão do Controle e Planejamento de Empreendimentos. Florianópolis, Autores, 2013, 512p.

Gestão Ambiental: Eco-

design e Prevenção de Conflitos. Diário Catarinense. Florianópolis, 2 ago. 2000. Caderno 1, p 1-8.

Gestão Ambiental: Mapeamento de Conflitos. Diário Catarinense. Florianópolis, 9 ago. 2000. Caderno 2, p 1-8.

Gestão Ambiental: Fatores de Conflitos. Diário Catarinense. Florianópolis, 16 ago. 2000. Caderno 3, p 1-8.

Gestão Ambiental: Analisando Problemas. Diário Catarinense. Florianópolis, 23 ago. 2000. Caderno 4, p 1-8.

Gestão Ambiental: Conflitos no Espaço e Tempo.

Diário Catarinense. Florianópolis, 30 ago. 2000. Caderno 5, p 1-8. 
Gestão Ambiental: Detectando Problemas. Diário Catarinense. Florianópolis, 6 set. 2000. Caderno 6, p 1-8.

Gestão Ambiental: Encontrando Soluções. Diário Catarinense. Florianópolis, 13 set. 2000. Caderno 7, p 1-8.

Gestão Ambiental: Implementando Soluções. Diário Catarinense. Florianópolis, 20 set. 2000. Caderno 8, p 1-8.

SOUZA, Edson. Conflitos e Negociação na Administração Pública. Instrucional Designer Carmem Maria Cipriano Pandini - Palhoça: UNISUL Virtual, 2006. 140p. 